\title{
Index of Potential Contamination for Intestinal Schistosomiasis among School Children of Raya Alamata District, Northern Ethiopia
}

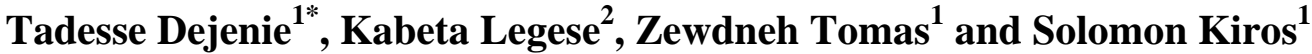

${ }^{1}$ Department of Biology, College of Natural and Computational Sciences,Mekelle University, P.O.Box 231, Mekelle, Ethiopia(*taddej2002@gmail.com)

${ }^{2}$ Department of Biology, MizanTepi University,P.O.Box 121, Tepi, Ethiopia

\begin{abstract}
Effective and sustainable control of Schistosomamansoni infection requires identifying subpopulations that are at risk of infection. A cross-sectional epidemiological survey was conducted in children of four primary schools in Raya Alamata District of Ethiopia to determine the prevalence and intensity of infection, and index of potential contamination of intestinal schistosomiasis. Fecal samples of 500 (266 males and 234 females) subjects aged 6-19 years were processed using Kato Katz thick smear field technique. Questionnaire survey was also deployedto assess associated risk factors among infected children. Out of the examined children, $101(20.2 \%)$ were infected by $S$. mansoni. The prevalence of infection differed significantly among the age groups $\left(\chi^{2}=6.93 ; \mathrm{P}<0.05\right)$. High prevalence of infection was observed among children of 10-14 years old. Intensity of S. mansoni infection was low, only $3.96 \%$ had heavy infection intensity. Children of 10-14 years age have high infection intensity than any age group $\left(\chi^{2}=12.5 ; \mathrm{P}<0.05\right)$. Index of potential contamination value showed that to a great extent children of 10-14 years were responsible to contaminate the environment with the bulk of $S$. mansoni eggs and for the transmission and maintenance of the disease in the area. Swimming habit $(\mathrm{AOR}=3.66 ; \mathrm{P}<0.05)$, frequency of water contact $(\mathrm{AOR}=8.15 ; \mathrm{P}<0.05)$ and treatment history (AOR 2.1; CI 1.3-3.3, P= 0.002) were the potential associated risk factors for S. mansoni infection. Schistosomamansoni infection did not show any significant association with gender, household water source, bathing and family occupation. Intestinal schistosomiasis is a public health problem, and to a great extent children of 10-14 years age group were responsible in the transmission and maintenance of the infection.
\end{abstract}

Key words: Ethiopia Infection prevalence, Schistosomiasis, IPC, Tigray,

\section{INTRODUCTION}

Global biodiversity loss and emergence of parasitic disease are the two most challenging issues confronting both science and society nowadays (Johnson et al., 2009). Intestinal parasitic infections especially helminthes infections are a major public health problem among children in the developing countries (WHO, 2008). Soil-transmitted helminths (STHs) and schistosomes are among the most prevalent helminth infestations of humans (Hotez et al., 2006).

Schistosomiasis is a chronic and debilitating neglected tropical disease affecting poor rural communities in sub-Saharan Africa where local populations seek water for cooking, drinking, 
washing and bathing at schistosomiasis transmission sites (King et al., 2004; Johnson et al., 2009). Over 280, 000 death per year in Africa is due to schistosomiasis of which 150,000 and 130,000 deaths are due to urinary schistosomiasis and intestinal schistosomiasis, respectively (Fenwick et al., 2003).

Schistosomamansoni is a parasite that is responsible for intestinal schistosomiasis in different localities of Ethiopia particularly in the northern and northwest parts (Moges et al., 2001; Mulugeta et al., 2011). Furthermore, intestinal schistosomiasis is reported to be endemic in different parts of Tigray (Tadesse and Tsehaye, 2008; Tadesse and Beyene, 2009; Lemlem et al., 2010). Introduction of water development projects and population movement for settlement and job opportunities have a great impact on the distribution and transmission of this disease in the country (Moges et al., 2001; Brhanu et al., 2002; Ghebreyesus et al., 2002).

This survey was conducted in school aged children because they are usually the highly vulnerable group and thus, should be first targeted group for intervention because of the detrimental effects the disease has on their growth and development (Bowie et al., 2004; John et al., 2008). Furthermore, they represent the infection status in the population as they consistently have highest prevalence and transmission of schistosomiasis and treatment via schools is also feasible and cost effective (Bowie et al., 2004).

Index of potential contamination (IPC) is most powerful predictive methodology and relevant epidemiological measures to identify the relative potential of different age groups at higher risk of infection and responsible for the transmission and spread of this disease in particular area than the use of prevalence and/or intensity (Junior et al., 1991; Vercruysse et al., 2001; Nale et al., 2003; Tetteh et al., 2004). The identification of risk factors for S. mansoni infection contributes to a better understanding of the transmission process and for the definition of control programs in particular localities (Ximenes et al., 2003).

Although several epidemiological studies for intestinal schistosomiasis due to $S$. mansoni infection were carried out in different parts of Ethiopia, none of them yet estimated the IPC of this disease (Hailu et al., 1994; Alemayehu et al., 1998; Brhanu et al., 2002; Alemshet et al., 2010; Mulugeta et al., 2011).Moreover, there is no updated information on the infection profiles and transmission potential of intestinal schistosomiasis of the current study site except a study conducted a decade ago on hundred schoolchildren of Gerjelle by Tadesse and Beyene (2009). 
However, health strategy for attainment of effective parasitic disease control programs demand knowledge on the magnitude of the disease and their changes in course of time with ecological, cultural, behavior and other factors. Therefore, the present study aimed to provide epidemiological data on themagnitude, intensity of infection, determinantsand potential transmission of $S$. mansoni infections among school children of Raya Alamata District, northern Ethiopia.

\section{MATERIALS AND METHODS}

The study was conducted from February 2012 to March 2012 in children of four primary schools of Raya Alamata District of Southern Zone of Tigray Regional State, northern Ethiopia. The study children were from Gerjelle, Facha, Babo Korma and Rarhe primary schools which are located on eastern side and the southern tip of Alamata town $(600 \mathrm{~km}$ away from the capital city of Ethiopia, Addis Ababa, and 183km from the capital city of Tigray, Mekelle), respectively (Fig 1). The district lies between longitude of $12^{\circ} 24^{\prime} 54^{\prime \prime}$ ' $\mathrm{N}$ and latitude of $39^{\circ} 33^{\prime} 42^{\prime}$ ' $\mathrm{E}$. The mean annual rainfall of the study area is $628.8 \mathrm{~mm}$ while annual temperature is between $18^{\circ} \mathrm{c}$ and $27^{\circ} \mathrm{c}$. The rainfall is scarce with the short rainy season followed by long dry season (BoPED, 1998). The district has about 84,997 inhabitants with a total area of $550 \mathrm{~km}^{2}$. Most of the inhabitants $(93.5 \%)$ of the district live in rural areas and based on irrigational and rain fed agricultural practices for their livelihood. The altitude of the district ranges from 1178masl to 31148masl. Most parts (75\%) of the district is lowland (<1500masl). It is bordered by Amhara region in the west and south, and by Ofla and Raya Azebo districts in northwest and east, respectively.

\subsection{Study Design and Population}

A cross-sectional descriptive study was conducted to determine the prevalence, intensity of infection and transmission potential of intestinal schistosomiasis in the study area. The study population was selected from four primary schools. And from these schoolschildren were selected as the study population because the prevalence of infection in school children can be used as an index for assessing community prevalence (Guyattet al., 1999) and they are likely to accept the inconvenience of providing stool specimens. 


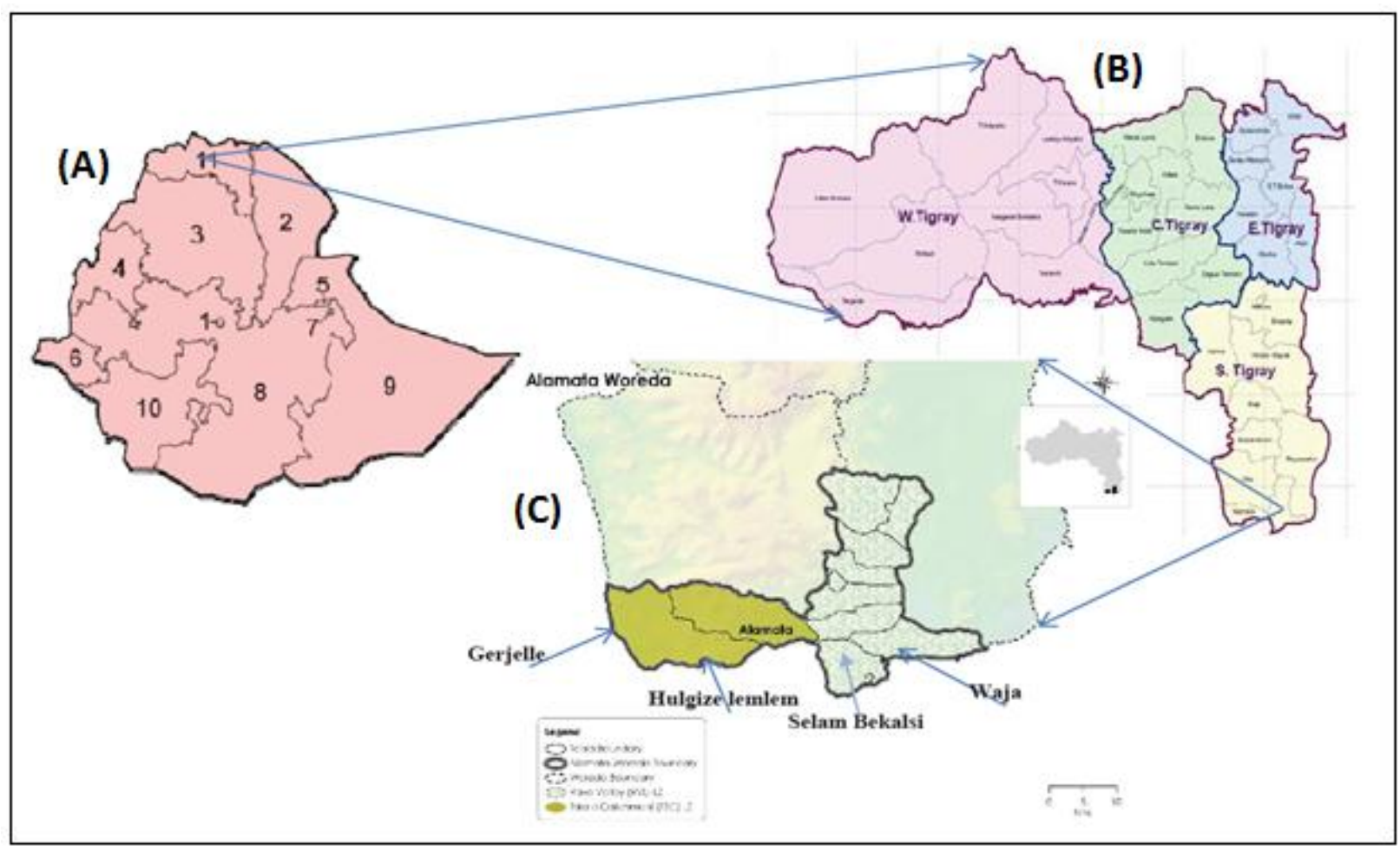

Figure 1. Map of the study area: (A) map of Ethiopia; (B) map of Tigray and (C) map of Raya Alamata District.

\subsection{Sample Size Estimation}

The minimum number of study subjects was estimated by using minimum sample size determination technique (Daniel, 1995; Thrustfield 2005). $\mathrm{n}=\frac{\mathrm{Z}^{2} \mathrm{P}(1-\mathrm{P})}{\mathrm{d}^{2}}$. Where $\mathrm{n}$ is minimum number of sample size $\mathrm{Z}$ is standard value, $\mathrm{P}$ is the prevalence value and $\mathrm{d}$ isabsolute precision. At $95 \%$ level of confidence $\mathrm{Z}=1.96$ and absolute precision is $5 \%$.Using the average prevalence report for Schistosoma infection from this area (Tadesse and Beyene, 2009), P-value was considered to be $50 \% . \mathrm{n}=\frac{(1.96)^{2}(0.5 \times 0.5)}{(0.05)^{2}}=384$

To minimize sampling error during sample collection, $25 \%$ of the estimated value (96 children) were added as contingency for non-response and missing data. However, 20 children were added since there was enough man power and resources. Then a total of 500 stool sample from children were taken as minimum sample size. Accordingly, 175, 125, 100, and 100 school children from Gerjelle, Babo Korma, Facha and Rarhe primary schools were involved as the study population, respectively. 


\subsection{Ethical Considerations}

The proposal of the study was reviewed and approved by Department of Biology, Mekelle University and ethically cleared by ethical clearance committee of Mekelle University Health Sciences College. A letter of participation in the study was also written to the study primary schools from Biology Department. The purpose, objectives and benefits of the study were also explained to school directors and to the students and consent for participation sought to participate in the study. Laboratory samples were taken only from those individuals who were volunteers. All children who tested positive for S. mansoni infection were treated with Praziquantel $(40 \mathrm{mg} / \mathrm{kg})$ and children tested positive for other intestinal helminthes infection were treated with albendazole (400 mg).

\subsection{Data collection and Laboratory Examination}

The students that were enrolled in the study schools during the sample collection were first stratified according to their educational level (grade 1 to grade 8) for sample selection. A quota was then allocated for each grade and each class room. Finally, the sample children were selected using systematic random sampling techniques using class rosters as the sampling frame. The selected children were then advised how they should bring their stool sample without exchanging and contaminating with the soil, and supplied with a piece of paper to bring about $3 \mathrm{gms}$ of their own stool sample. Those students who were not able to pass stool during sample collection were advised not to bring their friends stool, but to report that they could not able to pass stool and those reported were replaced by other.

The collected samples were processed by Kato Katz thick smear technique (Katz et al., 1962) in the field and transported to Mekelle University Parasitology and Microbiology laboratory for microscopic examination. One slide was prepared for each sample and examined once for the presence of eggs of S. mansoni and other intestinal helminthes. An individual was considered positive for S. mansoni or other helminthes infections if eggs of the respective parasites were observed in the Kato Katz slide preparation and an individual was considered negative for $S$. mansoni, all or any of the helminthes species if no ova were observed in Kato Katz slide preparation. Kato Katz slide preparations were performed using a template delivering $41.7 \mathrm{mg}$ of stool sample. Egg per gram (epg) of stool was calculated by multiplying 24 with egg counted under microscope during stool examination. Intensity of infection was estimated from the number of eggs per gram of stool (epg) for each parasite. Finally, classification of intensity of 
infection was carried out based on egg count for each parasite accordingly. Intensity of $S$. mansoni was classified into light (1-99 epg), moderate (100-399 epg) and heavy infections (> 400 epg). Finally, an index of potential contamination was calculated from the egg counts.

\subsection{Socioeconomic Survey}

Data of socioeconomic factors were collected using semi-structured questionnaires were employed to 237 children systematically. All questions were closed-ended in structure. Socio demographic data such as sex, age, educational status, behavioral pattern of water contact and frequency of water contact, and family occupation were gathered after the student brought their stool. Questionnaires were prepared in English and translated and administered to the student in their mother tongue, Tigrigna.

\subsection{Data analysis}

Data obtained were coded and entered into Microsoft office Excel, cleaned, edited and exported to SPSS version 16.0 for analysis. Chi-square test was used to test the relationship between demographic factors and infection prevalence and intensity using descriptive statistics of the sample through cross tabulations. The intensity of S. mansoni infection was categorized into light, moderate, and heavy using standard cut-off values based on egg counts. The environmental contamination of S. mansoni eggs was estimated using index of potential contamination (IPC) calculation (Vercruysse et al., 2001; Naleet al., 2003). Odds ratios (OR) was used to test the strength of the association between $S$. mansoni infections and risk factors. P-value less than 0.05 were considered to be significant.

\section{RESULTS}

A total of 500 children (266 males and 234 females) participated in this study. The age group of the children was 5-19 years. Most of the children, 277 (55.4\%) were between the ages of 10-14 years while the least, 31(6.2\%) were aged above 15 years. Out of examined children, 101 (20.2\%) were found to be positive for $S$. mansoni infection. Although the prevalence of $S$. mansoni infection was $54.45 \%$ for males and $45.54 \%$ for females, the prevalence of infection between female and male was statistically insignificant $\left(\chi^{2}=0.080 ; \mathrm{P}=0.085\right)$.A high significant difference was observed between $S$. mansoni infection and different age groups $\left(\chi^{2}=6.93 ; \mathrm{P}=\right.$ 0.006). The highest infection rate $(50.49 \%)$ was observed in 10-14 age group children followed by $47.52 \%$ and $1.98 \%$ for 5-9 and 15-19 years age groups, respectively. The prevalence of $S$. 
mansoni infection among the schools was also highly significant $\left(\chi^{2}=296.365 ; \mathrm{P}=0.000\right)$. The highest infection prevalence was observed in children of Babo Korma primary school (73.6\%) followed by those from Gerjelle (5.14\%). However, no S. mansoni eggs were detected from the stool sample collected from school children of Facha and Rarhe primary schools (Table 1).

Table 1. Prevalence of S. mansoni infection in the study schools, Raya Alamata, Northern Ethiopia.

\begin{tabular}{|lll|}
\hline Schools & No.(\%) examined & No.(\%) infected \\
\hline Gerjelle & $175(35)$ & $9(5.14)$ \\
\hline Facha & $100(20)$ & 0 \\
\hline Rarhe & $100(20)$ & 0 \\
\hline Babo Korma & $125(25)$ & $92(73.6)$ \\
\hline Total & 500 & $101(20.2)$ \\
\hline
\end{tabular}

This study also found a high significance difference in prevalence of intestinal schistosomiasis among the hamlets (small villages) of the study areas $\left(\chi^{2}=299.4 ; \mathrm{P}=0.000\right)$. The highest prevalence was observed among children from Gemea followed by Kunkura, Aroresha, and Babo Korma of Waja-tumuga peasant association. On the other hand, the least prevalence was recorded from hamlets of Gerjelle peasant association.

Ascarislumbricoides33 (6.6\%), Hymnelopsis nana 11 (2.2\%), Taeniaspp. 7 (1.4\%), Trichuristrichuira5 (1.0\%) andEnterobiusvermicularis4 $(0.8 \%)$ were other intestinal parasitic infections which were observed during stool examination. Since the slides were not examined within 30 minutes of stool collection and smear preparation, the status of hook worms' infections was unknown. Although the overall prevalence of intestinal parasites (3.2\%) in the study area was very low, intestinal schistosomiasis due to $S$. mansoni was the most prevalent parasitic infection followed $(20.2 \%)$ by soil-transmitted helminthes infection (7\%). There was no single case of Strongyloidesstercoralis infection in this study.

Out of 101 children who were found to be positive for S. mansoni infection, 69 (68.31\%) had light infection, 28 (27.72\%), moderate and 4 (3.96\%) heavy intensity of infection. Geometric mean egg counts of $S$. mansoni infection were highest in males (70.488 epg) and age group 1519 years (109.98epg). There was insignificant difference in egg load between two sexes $\left(\chi^{2}\right.$ $=2.17 ; \mathrm{P}=0.224)$. The intensity of $S$. mansoni infection was different among the age groups $\left(\chi^{2}=\right.$ 
12.5; $\mathrm{P}=0.046)$. The highest epg was observed among 10-14 years old children followed by 5-9 years old children while the least epg was observed among children of 15-19 age groups. With regard to schools, the highest egg count (480epg) was registered from children of Babo Korma primary school. Light to heavy infections was recorded for school children of Babo Korma. However, no heavy infection intensity was observed among school children of Gerjelle. The intensity of all the other intestinal parasites that was encountered during the stool examination was light infections.

The index of potential contamination was computed for 101 school children to determine the age group that are responsible for the transmission of this disease in this locality. The sum of the IPC values for all age groups was 3477.07. The IPC values also revealed that children of 5-14 years age range were responsible for $79.59 \%$ environmental contamination. The relative IPC (40.77\%) reached its peaks in children of 10-14 years old. This age group also bears the heaviest egg burden (Table 2).

Table 2. Calculation of index of potential contamination in S. mansoni carrier children, Raya Alamata District, Northern Ethiopia.

\begin{tabular}{|c|c|c|c|c|}
\hline Age group & Prevalence (\%) & $\begin{array}{l}\text { Geometric Mean } \\
\text { eggs }\end{array}$ & Crude IPC* & Relative IPC (\%) \\
\hline $5-9$ & 25 & 54 & 1350 & 38.83 \\
\hline $10-14$ & 18.41 & 77 & 1417.57 & 40.77 \\
\hline $15-19$ & 6.45 & 110 & 709.5 & 20.4 \\
\hline Total & 49.86 & 241 & 3477.07 & 100 \\
\hline
\end{tabular}

$*$ Crude IPC $=$ Prevalence $\times$ Geometric mean egg counts.

Swimming habit, frequency of water contact, and treatment historywere significantly associated with the prevalence of $S$. mansoni in the study area (Table 3). On the other hand, S. mansoni infection was not significantly associated with demographic factors, water contact during crossing, water source, washing clothes in reservoir/dams and river, availability of indoor latrine and tap water for bathing, duration of residence and family occupation. The minimum duration of stay in the study area for the study participants was less than a year and the majority of them was born and had grown in the area. Most parents (67.5\%) of the children had toilets, and the remaining (32.5\%) had no access to toilets and defecate in open field. 
Children having swimming in the water bodies, with high habit of water contact were more infected than those with no swimming habit (AOR 3.66; 95\% CI 2.42- 5.55, P $=0.000$ ) and children whose frequently have water contact were more infected than those who do not have frequent water contact (AOR 8.15; 95\% CI 4.556- 14.55, $\mathrm{P}=0.000$ ). Children who do have prevous history treatment were more infected than those who have not been treated previously $($ AOR 2.31; 95\% CI 1.3-13.3, $\mathrm{P}=0.002)$ (Table 3).

Table 3. Risk factors for S. mansoni infection among school children of Raya Alamata District, northern Ethiopia.

\begin{tabular}{|lllc|}
\hline Risk factors & AOR & COR & P-value \\
\hline $\begin{array}{l}\text { Water contact habit } \\
\text { Swimming }\end{array}$ & $3.66(2.42-5.55)$ & $0.12(0.05-0.3)$ & 0.000 \\
\hline $\begin{array}{l}\text { Frequencyof } \\
\text { water contact }\end{array}$ & $8.15(4.56-14.55)$ & $0.05(0.02-14.55)$ & 0.000 \\
Frequently & & & \\
\hline $\begin{array}{l}\text { Treatment history } \\
\text { Previously treated }\end{array}$ & $2.1(1.3-3.3)$ & $0.36(0.2-0.7)$ & 0.002 \\
\hline
\end{tabular}

\section{DISCUSSION}

This study is most probably the first in its kind in assessing IPC for $S$. mansoni infection among school children in Ethiopia. This survey registered a new focus of $S$. mansoni infection in seven hamlets and has added further evidence on the endemicity of intestinal schistosomiasis in the region.

The result obtained in this study is an indication of a public health problem of $S$. mansoni in the study area. This is in conformity with studies conducted among school children in different parts of the country (Moges et al., 2001; Brhanu et al., 2002; Mengistu et al., 2009; Alemshet et al., 2010; Habtamu et al., 2010; Mulugeta et al., 2011; Tadesse et al., 2009; Lemlem et al., 2010). The prevalence of intestinal schistosomiasis recorded in this study was very low as compared to previous studies (Hailu et al., 1994; Alemayehu et al., 1998; Tadesse et al., 2009; Lemlem et al., 2010) but higher than that reported by Tadesse and Tsehaye (2010) and Habtamu et al. (2010). This deviation could be due to difference in geographic condition, awareness of the community, modification towards parasitic infection, and prevalence of vectors and other environmental and biological factors in these areas (Ghebreyesus et al., 2002). 
In agreement to other research reports in different localities of Ethiopia (Alemayehu et al., 1998; Tadesse and Beyene, 2009;Habtamu et al., 2010), the current study recorded high significant difference of S. mansoni infection in different age groups. However, Tadesse and Tsehaye (2010) and Lemlem et al. (2010) reported that there was no significant difference in infection prevalence of $S$. mansoni in different age groups. This difference might be due to the difference in the water contact behavior of the study subjects in different localities at different age level.

High prevalence of S. mansoni infection was recorded among children of 10-14 years age group. This finding is in line with most studies reported from elsewhere and different parts of Ethiopia (Alemayehu et al., 1998; Nale et al., 2003; Tadesse and Tsehaye, 2008). This might be due to the longer time of exposure to the infection, as these age group children take higher position in helping their family in the farming areas. Besides, the children stay swimming for recreational purposes and they may also have low acquired immunity to the infection than other age group (Junior et al., 1991; Nale et al., 2003). Thus, more exposure to cercariae infected water and contract the diseases than any other age group.

The highest egg count was observed among children of 10-14 years old. This is in agreement with the studies conducted elsewhere (Nale et al., 2003; Bowie et al., 2004; John et al., 2008) and different parts of Ethiopia (Moges et al., 2001; Habtamu et al., 2010). In contrast with these studies, the study conducted in Jimma town by Mulugeta et al. (2011) found the highest egg count in children of 15-19 years age group. This difference might be due to the water contact pattern of different age groups in different areas. In our case, children of 10-14 age groups might have high water contact behavior, and due to other host specific factors (Hotez et al., 2006).

The present study recorded no significant difference in infection prevalence of $S$. mansoni between males and females. This finding is in agreement with Habtamu et al. (2010) finding in Southern parts of Ethiopia. However, several findings have been reported high infection prevalence of $S$. mansoni in males than in females from elsewhere (Nale et al., 2003) and different parts of Tigray (Tadesse et al., 2009; Lemlem et al., 2010; Tadesse and Tsehaye, 2010). This variation in infection could probably associated with difference in pattern of water contact activities in which it is higher and frequent in males than in females in these areas (Nale et al., 2003) due to work division in different communities and ethnic groups (Tadesse and Tsehaye, 2010), but in the present study no infection difference was observed between the two sexes 
because both sexes might have similar frequency and water contact behavior to contract the disease.

Most of the infected children were experienced light infection intensity of schistosomiasis with very few children experiencing heavy infection. This concentration of eggs in a small number of individuals with heavy infections underscores that the studied schistosomiasis were asymptomatic (Junior et al., 1991). This coincided with several studies conducted elsewhere (Junior et al., 1991; Nale et al., 2003; John et al., 2008) and several parts of Ethiopia (Moges et al., 2001; Brhanu et al., 2002; Mengistu et al., 2009; Alemshet et al., 2010; Habtamu et al., 2010; Lemlem et al.,2010; Mulugeta et al., 2011). Thus, the infected children do not experience serious illness that enforces them to search for treatment but they keep on maintaining the disease in the area by contaminating the environment with the eggs of the parasite.

The prevalence of $S$. mansoni showed the highest infection rate in children from schools located in vicinity to river and irrigation water $(73.6 \%)$ followed by those from schools nearby to the longstanding irrigated areas (5.14\%), and no infection was recorded where the school children stay in un-irrigated areas and no contact with water body. This is in agreement with the study conducted elsewhere and in several parts of Tigray (John et al., 2008; Tadesse et al., 2009; Tadesse and Beyene, 2009; Tadesse and Tsehaye, 2010). In addition, the intensity of infection also showed variation within the study schools. This variation in infection indices might be associated with location of the school, behavioral pattern of children towards water body, and presence or/and absence of responsible intermediate host snail for the transmission of the parasite and water body for the parasite to complete its life cycle (Ghebreyesus et al., 2002; Tadesse and Tsehaye, 2010).

The highest light intensity of S. mansoni infection was recorded in children from Babo Korma school where children have high contact with river and irrigation water from Aroresha river that come down from Waja, a schistosomiasis endemic areas (Tadesse et al., 2009; Tadesse Beyene, 2009) followed by that of Gerjelle where irrigation practices is on the way to collapse due to water scarcity, and river water is far away. In areas where rain fed agriculture is only a means of livelihood practices, no $S$. mansoni infection was recorded, which is similar to previous studies (Alemayehu et al., 1998; Tadesse and Tsehaye, 2008; Tadesse and Beyene, 2009). Heavy infection was reported only from Babo Korma primary school. In other word, no heavy infection intensity was recorded from school children of Gerjelle. The difference in infection intensity 
among the schools might be due to the difference in the availability of water body in the nearby environment and water contact behavior of the children of the two schools. Children from Babo Korma have more chance to have contact with schistosomiasis infected water than children from Gerjelle. Furthermore, the infection prevalence of intestinal schistosomiasis also differs among the hamlets. Hamlets in close vicinity to water body showed higher prevalence of infection than those are away from water body. This is in agreement with the finding of Tadesse and Tsehaye (2008) from school children in Hintallo-Wejerat, and Tadesse and Beyene (2009) in Central and South Tigray. This could be attributed to the availability of water bodies which create a favorable environment for the multiplication of snail intermediate host (Tadesse et al., 2009) and children from hamlets that were in close proximity to water body have higher chance to be exposed to cercariae infested water than those children that were from the hamlets far away from water body.

The IPC is an important epidemiological tool to evaluate the transmission and to identify the age group of the study population responsible for the maintenance of the disease in particular area (Junior et al., 1991; Vercruysse et al., 2001;Nale et al., 2003; Tetteh et al., 2004). Although IPC is a relevant epidemiological measure for schistosomiasis, it is the first time to be used here in Ethiopia. Calculation of IPC for intestinal schistosomiasis in the study area revealed that children within 5-14 age range are potentially responsible to contaminate the environment with bulk of $S$. mansoni eggs and thus, for the transmission of the disease in these localities. This finding is in agreement with the finding of Tetteh et al. (2004) from Ghana but in contrast to Nale et al. (2003) finding from Nigeria, 5-19 years old children were responsible for both contamination and transmission of this disease. This might be explained in environmental, behavioral and ecological difference between these study areas. However, in agreement to Nale et al. (2003) finding, this study also found children of 10-14 years bear the heaviest egg burden among the age structure and found to be the most important contributor of the environmental contamination. The other special finding of this study is the new infection foci report of $5.14 \%$ infection prevalence of $S$. mansoni in Gerjelle, which was previously reported no record of schistosomiasis a decade ago (in 2002) (Tadesse and Beyene, 2009). This deviation from the previous finding might be due to new introduction of the parasite to this area through population movement for settlement and job opportunity from schistosomiasis endemic areas to this area (Ximenes et al., 2003; King et al., 2004; WHO, 2008) or/and aquatic birds and snail might be introduced from 
infected streams and rivers as predicted by the earlier investigators (Tadesse and Beyene, 2009), and it might also be due to the difference in sample size. The low prevalence of schistosomiasis in this area could also be the disease might reached its peak within these ten years and declined due to the collapse of the irrigation practices in the environment (King et al., 2004) or/and it is a recently introduced (Habtamu et al., 2010) and thus, is not established in the area. Thus, if the disease is a recently introduced, concerned body should place appropriate mitigation strategies to mitigate the disease before the environment is polluted by the bulk of $S$. mansoni eggs, and the disease is established and its magnitude is increased in the society.

Questionnaires are well accepted and operationally feasible to screen communities at highest risk of S. mansoni infection, and are faster and less expensive than standard parasitological diagnoses. The present study found different factors that were associated with the infection prevalence of S. mansoni in the study subjects (Johnson et al., 2009). Children who have frequent water contact and swimming habit harbored the parasite than who have low water contact during their different activities. This coincided with the findings of Matthys et al. (2007) and Enk et al. (2010). This might be due to the higher chance of exposure to the infective stage of $S$. mansoni parasite of children who have swimming and frequent activities of water contact (King et al., 2004; WHO, 2008). Infection among untreated children was high because the effective drug treatment (Fenwick et al., 2003) may reduce the eggs output in the infected individuals. Generally, the prevalence of intestinal parasites among the study subjects was very low. A decline in the percentage of infection observed in the present study may be attributed to the increased literacy level that must have led to improved sanitation with resultant reduction in the level of environmental contamination and consequent exposure to the disease. A more plausible reason is the possibility in the demographic setting of the community, thus changing both the behavioral attitude and values.

\section{CONCLUSION}

The present study has clearly indicated the prevalence of $S$. mansoni infection in the study area and reported two new infection foci, Gerjelle and Babo Korma. IPC values revealed that children of 10-14 years age range weremostly impacted by heavy eggs burden and take the higher position in contamination of the environment with the eggs of S. mansoni. They also represent the main transmission group and most important age groups in maintaining the disease in 
thelocality. Thus, age group should be targeted for control and treatment. Water supply and sanitary conditions of the society should be maintained through education and awareness creation to reduce the overall worm burden. Further study incorporating snail survey and awareness level of the community should be conducted to ensureeffective and sustainable control of schistosomiasis in this area.

\section{ACKNOWLEDGMENTS}

The authors would like to thank study subjects for supplying their stool and Mekelle University for financial support. Special thanks are due to Mr. Atsbeha Gebrekidan for his laboratory technical support. The comments and suggestions provided by the reviewers Dr. Endalkachew Nibret and Dr. Berhihun Afera are highly appreciated and duly acknowledged.

\section{REFERENCE}

Alemayehu, T., Yebiyo, Y., Gherbreyesus, T \& Wtten, K. 1998. Malaria, schistosomiasis and intestinal helminthes in relation to micro dams in Tigrya, Northern Ethiopia.Parasitol, 40: $259-267$.

Alemshet, Y., Sileshi, K \& Yoseph, M. 2010. Impact assessment of Gilgel Gibe Hydroelectric dam on schistosomiasis, Southwest Ethiopia. Ethiop J Health Sci., 21: 129-136.

Bowie, C., Purcell, B., Shaba, B., Makaula, P \& Perez, M. 2004. A national survey of the prevalence of schistosomiasis and soil transmitted helminths in Malawi. BMC Infect Dis, 4: $49-58$.

Brhanu, E., Girmay, M., Nega, B., Fekadu, A., Tashome, G \& Svein, G. 2002. Epidemiological studies on intestinal schistosomiasis in Wondo Genet, southern Ethiopia. Ethiop Med J., 40: $29-39$

Bureau of Planning and Economic Development (BoPED). 1998. Atlas of Tigray, pp.3-24.

Daniel, W. 1995.Biostatics a foundation for analysis in health science. $6^{\text {th }}$ edition, John Willey and Sons inc. New York, USA.

Enk, J., Lima, L., Barros, D., Masarra, L., Coelho, Z \& Schall, T. 2010. Factors related to transmission and infection with $S$. mansoni in village in the Southern eastern Brazil. Mem. Inst. Oswaldo Cruz, 105: 570-577. 
Fenwick, A., Savioli, L., Engels, D., Bergquist, R \& Todd, H. 2003. Drugs for the control of parasitic diseases: Current status and development in schistosomiasis. Trends Parasitol, 19: $509-15$.

Ghebreyesus, T., Witten, K., Getachew, A., Haile, M., Yohannes, M., Lindsay, S \& Byass, P. 2002. Schistosome transmission, water-resource development and altitude in northern Ethiopia. Ann. Trop. Med. Parasitol., 96: 489-95.

Guyatt, L., Brooker, S \& Donnelly, A. 1999. Can prevalence of infection in school aged children be used as an index for assessing community prevalence? Parasitol, 51: 83-88.

Habtamu, M., Mengistu, L., Zelalem, T \& Berhanu, E. 2010. Transmission of Schistosomamansoni in TikurWuha area, Southern Ethiopia. Ethiop J Health Dev., 24: 180-184.

Hailu, B., Tilahun, W., Abraham, R \& Chane, T. 1994. The status of Schistosomamansoni and snail hosts in Tigray and northern Wello regions, northern Ethiopia. Ethiopia Med. J., 32: 245-54.

Hotez, J., Bundy, A., Beegle, K., Brooker, S., Drake, L., de Silva, N., Montresor, A., Engels, D., Jukes, M., Chitsulo, L., Chow, J., Laxminarayan, R., Michaud, M., Bethony, J., CorreaOliveira, R., Shu-Hua, X., Fenwick, A \& Savioli, L. 2006. Helminth Infections: Soil transmitted helminth infections and schistosomiasis. In: T. Jamison, G. Breman, R. Measham, G. Alleyne, M. Claeson, B. Evans, P. Jha, A. Mills, and P. Musgrove (eds.). Disease Control Priorities in Developing Countries, $2^{\text {nd }}$ edition, Washington DC, pp. 467-482.

John, R., Ezekiel, M., Philbert, C \& Andrew, A. 2008. Schistosomiasis transmission at high altitude crater lakes in Western Uganda. BMC Infect. Dis., 8:110.

Johnson, J., Lund, J., Hartson, B \& Yoshino, P. 2009. Community diversity reduces Schistosomamansoni transmission, host pathology and human infection risk. Proc. R. Soc. B, 276: 1657-1663.

Junior, M., de Jesus Patucci, M., de souza Dias, C., Hotta, K \& Etzel, A. 1991. Schistosomamansoni in area of low transmission: Impact of control measures. Rev. Inst. Med. Trop. Sao Paulo., 32: 83-90.

Katz, N., Chaves, A \& Pellegrino, J. 1972. A simple device for quantitative stool thick-smear technique in Schistosomiasismansoni. Rev. Inst. Med. Trop. Sao Paulo, 14:397-400. 
King, H., Blanton, E., Muchiri, M., Ouma, H., Kariuki, C., Mungai, P., Magak, P., Kadzo, H., Ireri, E \& Koech, K. 2004.Low heritable component of risk for infection Intensity and infection-associated disease in urinary schistosomiasis among Wadigo Village populations in Coast Province, Kenya. Am. J. Trop. Med. Hyg., 70: 57- 62.

Lemlem, L., Berhanu, E \& Asrat, H. 2010.Current status of intestinal schistosomiasis and soiltransmitted helminthiasis among primary school children in Adwa Town, Northern Ethiopia. Ethiopian J. Health Dev., 24: 191-197.

Matthys, B., Tschannen, A., Tian-Bi, N., Comoé, H., Diabaté, S., Traoré, M., Vounatsou, P., Raso, G., Gosoniu, L., Tanner, M., Cissé, G., N'Goran, E \& Utzinger, J. 2007. Risk factors for Schistosomamansoni and hookworm in urban farming communities in western Côte d'Ivoire. Trop. Med. Int. Health,.12: 709-23.

Mengistu, L., Jones, R., Singh, K., Berhanu E \& Yalemtsehay, M. 2009. Community's awareness about intestinal schistosomiasis and the prevalence of infection in two endemic localities of Ethiopia. Ethiopian J. Health Sci., 19:104-110.

Moges, T., Mesganaw, F., Afework, K., Gebeyaw, T., Van Lieshout,L \& Polderman, M. 2001. Schistosomiasismansoni in school attenders and non-attenders in Northwest Ethiopia. Ethiopian J. Health Dev., 15: 117-123.

Mulugeta, M., Techalew, S., Workneh, T., Ashenafi, T., Tesfaye, K \& Asrat, H. 2011.Human intestinal schistosomiasis in communities living near three rivers of Jimma Town, Southwestern Ethiopia. Ethiop. J. Health Sci., 21: 111-118.

Nale, Y., Galadima, M \& Yakubu, S. 2003. Index of potential contamination of urinary schistosomiasis in five settlements near river kubanni in Zaria. The Nigerian J. Parasitol, 24: 95-101.

Tadesse, D \& Beyene, P. 2009. Irrigation practices and intestinal helminth infections in southern and central zones of Tigray. Ethiopian J. Health Dev., 23: 48-56.

Tadesse, D \& Tsehaye, A. 2008.Impact of irrigation on the prevalence of intestinal parasite infections with emphasis on schistosomiasis in Hintallo-Wejerat, North Ethiopia. Ethiopian J. Health Sci., 18: 33-38.

Tadesse, D \& Tsehaye, A. 2010.Schistosomiasismansoni among school children of different water Source users in Tigray, Northern Ethiopia. Momona Ethiopian Journal of Science, 2: 49-60. 
Tadesse, D., Tsehaye, A \& Mekonnin, T. 2009.Intestinal helminthes infections and re-infections with special emphasis on Schistosomiasismansoni in Waja, North Ethiopia. Momona Ethiopian Journal of Science, 1: 4-16.

Tetteh, K., Adjie, O., Sasu, S \& Appiah-wakye, 2004. Index of potential contamination: Schistosomahaematobium infections in school children in Ashanti region of Ghana. East African Med. J., 84: 520-523.

Thrustfield, M. 2005. Veterinary Epidemiology. 3rd Edition, Blackwell Science Ltd., Cambridge, USA, pp.225-228.

Vercruysse, J., Shaw, D \& De Bont, J. 2001. Index of potential contamination for schistosomiasis. Trends Parasitol, 17: 256-61.

World Health Organization (WHO). 2008. The social context of schistosomiasis and its control: An introduction and annotated bioblography. WHO, Geneva, 213p.

Ximenes, R., Southgate, B., Smith, G \& Neto, G. 2003. Socioeconomic determinants of schistosomiasis in an urban area in the Northeast of Brazil. Pan Am. J. Public Health, 14: 409-420. 